\title{
A NEW TECHNIQUE FOR INTERGRANULAR CRACK FORMATION ON ALLOY 600 STEAM GENERATOR TUBING
}

\author{
Tae Hyun Lee \\ Seoul National Univ., 56-1, Shillim, \\ Kwanak, Seoul, Korea, 151-742 \\ Phone: 82-2-880-7200, \\ Fax: 82-2-3285-9600 \\ E-mail: ehfaks2@snu.ac.kr \\ II Soon Hwang \\ Seoul National Univ., 56-1, Shillim, \\ Kwanak, Seoul, Korea, 151-742 \\ Phone: 82-2-880-7215, \\ Fax: 82-2-889-2688 \\ E-mail: hisline@snu.ac.kr
}

\author{
Young Jin Oh \\ Seoul National Univ., 56-1, Shillim, \\ Kwanak, Seoul, Korea, 151-742 \\ Phone: 82-2-880-7200, \\ Fax: 82-2-3285-9600 \\ E-mail: yjoh2@peacer.org \\ Han Sub Chung \\ Korea Electric Power Research Institute, \\ 103-16 Mungi, Yusung, Taejon, Korea, \\ E-mail: hschung@kepri.re.kr
}

\author{
Jang Yul Park \\ Argonne National laboratory, 9700 S. Cass Avenue, Argonne, IL 60439, U.S.A \\ E-mail: jypark@anl.gov
}

\begin{abstract}
For the integrity management of SG tubes, non-destructive-evaluation performed using eddy-current-test (ECT) is necessary in the assessment. The reliability of ECT evaluation is dependent on accuracy of ECT on various kinds of defects. For basic calibration and qualification of these techniques, cracked SG tube specimens having mechanical and micro-structural characteristics of intergranular cracks in the field, were needed. To produce libraries of Laboratory-Degraded-SG-tubes (LDT) with intergranular cracks, a radial denting method and direct tension method were explored for generating ID and OD axial and circumferential crack by three-dimensional finite-element-analysis and experimental demonstration, respectively. The technique is proven to be applicable for generating axial cracks with long and shallow geometry as opposed to semi-circular crack typically obtained by internal-pressurization method. In addition, DCPD method applied with array probes was developed for accurate monitoring and controlling of crack size and shape. By these methods, long and shallow intergranular axial cracks being more typical of actual degraded SG tubes were successfully produced.
\end{abstract}

Keywords: Alloy 600-steam generator tubing, laboratory degraded tube (LDT), direct current potential drop (DCPD), finite element method (FEM), eddy current test (ECT)

\section{INTRODUCTION}

For the life management of nuclear power plants, the integrity assessment of steam generator tube plays an important role. Especially, non-destructive evaluation, burst pressure and leak rate prediction constitute techniques in the assessment.

Non-destructive evaluation and the failure prediction of steam generator tubes are periodically performed using eddy current test (ECT). Based on this result, repairs of degraded tubes and preventive measures are applied. 
The reliability of ECT evaluation is strongly dependent on flaw sizing, detection ability, and accuracy of ECT on various kinds of defects formed in tubes. However, there is a limitation in the current practice in improving reliability because electrical discharge machined (EDM) standard specimens used in the present ECT are fundamentally different from actual defects occurred in the field. Therefore they can not calibrate an exact ECT signal using the actual defects. In order to conduct basic characterization and calibration of these key techniques, a number of cracked tube specimens, having mechanical and micro-structural characteristics with intergranular cracks in the field, are needed. But, manufacturing technique of this kind of specimen is involved and not well established. A few research laboratories around the world have succeeded in manufacturing these specimens. But the specimens produced even in these laboratories are limited to more or less semi-circular crack geometry. Actual cracks in SG tubes are often found with high surface length to depth ratio (aspect ratio) higher than 10 on both inner and outer sides of a tube. [1, 3] In this thesis, a radial dent loading method to introduce axial intergranular cracks with high aspect ratios have been explored using sensitized Alloy 600 tubes as a procedure to generate a library of laboratory degraded tubes (LDT) for ECT qualification. Figure 1 shows the schematic of goals and approach of this thesis. Based on three-dimensional finite element analysis and preliminary experimental work, the radial denting method is shown to be more useful than the conventional internal pressurization method for the production of cracks with high aspect ratio. For the production of a library of LDT, it is desired to improve these methods so that cracks with high aspect ratio can be made in a controlled manner. It is desirable to employ on-line crack monitoring techniques such as direct current potential drop (DCPD) if probes are accessible. [4]

\section{MATERIALS AND FINITE ELEMENT ANALYSIS}

A commercial heat of Alloy 600 tubes with $0.025 \%$ carbon produced for nuclear steam generators of Korean Standard Nuclear Power Plant (KSNPP) has been obtained for this study. Tubes have $19.05 \mathrm{~mm}$ outer diameter and $1.2 \mathrm{~mm}$ thickness with a microstructure corresponding to a high temperature mill annealed (HTMA) condition. The chemical compositions and mechanical and metallurgical tests of this SG tube are listed in Table 1 and 2. These tubes were furnace-sensitized and then were cracked by exposing them to a $0.1 \mathrm{M}$ aqueous solution of sodium tetrathionate $\left(\mathrm{Na}_{2} \mathrm{O}_{6} \mathrm{~S}_{4} \cdot 2 \mathrm{H}_{2} \mathrm{O}\right)$ at room temperature and atmospheric pressure. [7] The solution was exposed to a limited area on test specimen by using lithography and micro shielding to make the crack in a wanted area.

In order to understand sensitization behavior of Alloy 600 tubes, tube specimens were heat-treated in several different conditions. The method of sensitization measurement refers to ASTM Method A 262. Each tube was given a sensitization treatment by aging at $600^{\circ} \mathrm{C}$ in $5 \%$ hydrogen and $95 \%$ argon gas atmosphere, for $24 \mathrm{~h}, 36 \mathrm{~h}$, $48 \mathrm{~h}, 60 \mathrm{~h}$ and $72 \mathrm{~h}$, respectively. Modified Huey tests in $25 \%$ boiling nitric acid were conducted for 24 hours to measure weight losses by intergranular attack. [6] It measures a mounts of mass dissolution due to chromium depletion. In other words, as the weight loss is larger, the thermal treated specimen is more sensitized. Table 3 shows weight loss data of both sensitized and as-received tubes. As shown in Table 3, Alloy 600 tubes used in experiments were effectively sensitized by 48 hours heat-treatment at $600^{\circ} \mathrm{C}$. Based on this test result, before an exposure to the tetrathionate solution, the specimens were heat treated at $600^{\circ} \mathrm{C}$ for 48 hours in reducing atmosphere to produce a microstructure that is susceptible to intergranular corrosion cracking in the aqueous solution. [6]

Tension test specimens with a reduced section length of $30 \mathrm{~mm}$ and width of $6.25 \mathrm{~mm}$ were prepared from tubes by electro discharge machining (EDM) without disturbing the curvature of tube in the circumferential direction. ASTM Method E8 has been followed for testing at room temperature with the loading axis in the tube length direction. [8] The tensile test results show that ultimate tensile and yield strengths of the as-received mill-annealed tubes are $660 \pm 10 \mathrm{MPa}$ and $280 \pm 10 \mathrm{MPa}$, while the corresponding values for the heat-treated tubes are $660 \pm 10 \mathrm{MPa}$ and $270 \pm 10 \mathrm{MPa}$, respectively. Yield strength is only negligibly affected by the sensitization treatment.

Preliminary stress corrosion cracking experiment was carried out to estimate crack initiation time of sensitized alloy 600 SG tube. By using tension specimen that is the same as those used in tube tensile test, crack initiation time was measured at various concentrations of sodium tetrathionate and axial tensile stress conditions. Crack initiation is observed by in-situ optical monitoring using long-focused microscope, Questar QM100. For more convenient monitoring, the aqueous solution exposes to a limited area by applying micro-shield paint at non-observation area. Under each test condition, two specimens were tested. Figure 2 represents average value of crack initiation time and its corresponding scatter. As shown in Figure 2, crack initiation time results show that the specimens at $90 \%$ yield stress condition took about 4 days, while the crack initiation time at $95 \%$ yield stress condition was about 2 days, respectively. This results shows that crack initiation time tends to be more influenced 
by a stress than the morality of sodium tetrathionate.

For the production of a long-shallow axial crack, the radial denting method is explored in this work. Figure 3 (a) and (b) show a schematic of the radial denting method applied for axial cracking at either outer or inner wall surface. Two and three-dimensional finite element analysis (FEA) were performed for the radial denting method in order to check the adequacy of stress state using ABAQUS 6.2-1. Figures 4 and 5 (a) show mesh structures employed for the tube and its cross-section, respectively, taking into account a four-fold symmetry. Figure 5 (b) shows the resultant stress distribution in the tube under the dent loading. Earlier studies with sensitized Alloy 600 showed that intergranular crack could be obtained, if tensile stress equal to $90 \%$ of yield strength is applied. Figure 6 shows predicted circumferential stress as function of applied dent load. It is shown that dent loading of $18.6 \mathrm{kN}$ and $35.6 \mathrm{kN}$ is required per one meter of axial length to obtain $90 \%$ of yield strength at Point 1 and Point 4 , respectively. The highest tensile stress is expected at Point 1 where $90 \%$ of yield strength can be achieved without inducing any significant plastic deformation in a tube. Therefore the radial denting method is shown to be suitable for axial crack production at the inner wall. At the outer wall, the tensile stress reaches a maximum at Point 4 . The extent of plastic deformation is also predicted based on FEA, as shown in Figure 7. Diametric changes are predicted for loading up to $35.6 \mathrm{kN} / \mathrm{m}$ and subsequent unloading. Displacements at Points 1 and 3 are negative whereas those at Points 2 and 4 are positive. After the complete unloading, residual plastic deformation is limited to about $5 \mu \mathrm{m}$ on the diameter that is too small to be detected by ECT, as shown in Figure 7. Therefore the radial denting method is expected to be applicable to produce axial crack at the outer wall as well.

In order to confirm the accuracy of three-dimensional FEA, a vertical diameter of a tube had been measured by using a micrometer before and after a radial dent loading up to $40 \mathrm{kN} / \mathrm{m}$ corresponding to $100 \%$ yield strength at point 4 . Figure 8 shows both measured and predicted vertical diameter. Measured vertical diameter varies with length at the greater extent than the predicted values. However there is a good agreement between two in peak changes in vertical diameters. Again, it is shown when the applied load is increased to obtain $100 \%$ of yield strength at Point 4, the plastic displacement becomes excessive. Therefore the maximum load should be limited to that corresponding to $90 \%$ of yield strength at Point 4 . At both Point 1 and Point 4, tensile stresses are expected to decrease rapidly in the thickness direction compared with changes in the axial direction. As the crack grows in the thickness direction, the grow rate can be reduced due to the stress decrease. Therefore a long axial crack with shallow depth is expected from this method. Such a high aspect (length-to-depth) ratio would represent typical field cracks that can be attributed to high surface residual stress of tubes.

A three-dimensional finite element analysis (FEA) was also performed for the direct tensile loading analysis in order to check the adequacy of stress state and the reliability of tube specimen design using ANSYS 7.0. Figures 9 shows mesh structures employed for the tube taking into account a four-fold symmetry. Because SG tube specimen is processed to have pin hole, designed to transmit tensile force to tube, shear stress analysis is needed to prevent failure of specimen by shear force at pin-hole area. Figure 10 (a), (b), (c) show predicted shear stress, Von Mises stress and axial stress, respectively. From the Figure 10, it is shown that the SG tube specimen was subjected to plastic deformation at pin-hole area after applying $90 \%$ of yield strength, but this plastic deformation in pin-hole region does not influence in stress distribution at tube center area where circumferential crack was generated. In this case, because shear stress formed at the pin-hole region does not reach the yield strength of SG tube specimen, it can be said that SG tube specimen is free from the risk of fracture while testing. When tensile load of $14.7 \mathrm{kN}$ is applied through the pin, tensile stress of about $200 \mathrm{MPa}$ is formed uniformly at the region generated crack. This value of stress is corresponding to $90 \%$ of yield strength of SG tube. From FEA result, direct tensile loading method, introduced to generate circumferential crack, is shown to have sound mechanical basis.

\section{INTERGRANULAR CRACK FORMATION ON STEAM GENERATOR TUBING}

\subsection{Production of OD cracked tubes}

Based on the supporting conclusion from FEA, a dent loading experiment was performed to produce an axial crack and succeeded in the crack production at room temperature. As shown in Figure 11, the tube specimen was compressed by a pair of denting jigs over an axial length of $10 \mathrm{~cm}$ and a direct current potential drop was applied with about $2 \mathrm{~mm}$ wide probe spacing. In parallel, the crack evolution was checked using a traveling microscope installed in front of the tube. Except for the front rectangular opening area that is predicted to have high tensile circumferential stress, all other surfaces were masked with paint either manually or by lithography technique to avoid spurious crack initiations. No crack was detected at the design test load corresponding to $90 \%$ of yield strength up to 48 hours. To accelerate cracking to proceed to the next series of investigations, the load was increased stepwise until a crack was observed above $90 \%$ of yield strength. Figure 12 (a) shows a surface crack 
that occurred in the specimen but at a load in excess of $100 \%$ of yield strength. The crack has about $1 \mathrm{~mm}$ axial length on the surface. A significant crack opening was evident due to excessive loading. The second cracking test was conducted over a longer time period using the same load level. A long axial crack has been obtained as shown in Figure 12 (b). Total crack length is found to be $17.65 \mathrm{~mm}$. In Figure 13, the numbers denotes DCPD probe located. At each DCPD probe location, cracked tube was sectioned for confirming the crack depth. Then each section was observed by using optical microscope. The photomicrographs, observed at each DCPD probe located, are summarized in Figure 13. The crack depth was ranged from $0.55 \mathrm{~mm}$ to $1 \mathrm{~mm}$. Aspect ratio of OD axial crack of $17.65 \mathrm{~mm}$ was more than 16. Because general aspect ratio of field degraded SG cracked tube is about 10, radial denting method is shown to be very useful method that generated cracked specimen having a high aspect ratio.

A few research groups have succeeded in the production of LDT circumferential crack by using tensile load. Argonne National Laboratory (ANL) and Korea Atomic Energy Research Institute (KAERI) have established a room temperature cracking procedure using direct tensile load. [2] From the reports of these research groups, the tension loading are expected to be convenient and inexpensive for the production of cracks. Only, design of jig for loading differs in this work from those of above research group. Based on FEM analysis, circumferential crack generation is confirmed to be feasible without any difficulty. In the first direct tensile loading test a crack was detected at the design test load corresponding to $90 \%$ of yield strength for up to about 80 hours. Figure 14 shows photograph of crack that occurred in the specimen. But, as shown in Figure 14, this surface crack was excessively loaded by operation glitches of Instron test machine in process unloading after detecting formation of crack. For confirming depth and shape of circumferential crack before the rupture, scanning electron microscope (SEM) observation on fracture surface was performed. Figures 15 (a), (b) show sectioned areas of the cracked tube for SEM observation, SEM photomicrograph of whole section of tube wall containing intergranular stress corrosion cracked area and ruptured area, respectively. As shown in Figures 14 and 15 (b), circumferential crack had a length of $4 \mathrm{~mm}$ and a maximum depth of $0.88 \mathrm{~mm}$. From observation by using SEM micrograph, intergranular stress corrosion circumferential crack could be made successfully through direct tensile loading method. By using DCPD value corresponding to each depth of crack, it was confirmed that cracked specimen of wanted depth can be made in subsequent experiments. This will be described in detail in next chapter.

\subsection{Production of ID cracked tubes}

By using radial dent loading method, the cracked tube on inner wall was produced. Figure 16 shows an overview of apparatus for ID axial crack generation. To give positive proof of inner wall crack generation, an experiment to confirm initiation condition of crack was conducted using an optical monitoring method. A mirror was inserted in the inside of tube and the surface condition of inner wall was monitored using long-focus microscope, as shown in Figure 17. After the experiment to confirm the initiation condition of crack, a main experiment using DCPD method was performed. Figure 18 shows photograph of crack that occurred in the test specimen. As shown in Figure 18, the ID cracked tube was cut in half for confirming the crack shape. Photomicrographs for $15.5 \mathrm{~mm}$ crack and $9.9 \mathrm{~mm}$ crack were put together, so long and shallow crack with total length of $25.4 \mathrm{~mm}$ was generated. Then the cracked tube was sectioned to confirm the crack depth at each position located DCPD probe. The crack depth was ranged from $0.8 \mathrm{~mm}$ to $1.1 \mathrm{~mm}$, as shown in Figure 19.

\section{IN-SITU DCPD MONITORING}

\subsection{Sensitively analysis of DCPD using Finite Element Analysis of Electromagnetic}

To control and monitor the initiation and propagation of a crack, Direct Current Potential Drop (DCPD) method was introduced in this study. This DCPD method will be a key technology to generate axial and circumferential crack with desired depth and length at a desired position of inner or outer wall of steam generator tube. In DCPD method, potential difference is increased by increase of electric resistance with crack growth. This is crack length measuring method that is used widely in fracture mechanics of conducting materials. In this study, potential differences at several positions of crack length direction were measured using array probes, for monitoring shape and position of crack. The shape and depth of crack were assessed by comparing DCPD measurements with FEA simulation. The FEA performed in order to verify the measured results and to estimate its sensitivity.

Prior to an experiment, sensitivity analysis on DCPD was conducted using FEA. Results were compared with Johnson Equation on DCPD experiment for compact tension specimen, by using ANSYS Release 7.0. Figures 20 (a) and (b) show schematic of sensitivity analysis and FEM meshing model, respectively. Current input wires and potential output leads are placed according to ASTM Method E 1737-96, that is a previous version of ASTM 
Method E 1820-99. [5] Current input wires were attached to the top and bottom edges at W/4 from the load line, as described in Figure 20 (a). One of the potential leads was placed near one side and the other near the other side, in an attempt to detect average crack length. Before comparison, Johnson's theoretical normalized potential data as a function of normalized crack length is shown in graphic form in Figure 21. Figure 22 (a), (b) show potential contours of CT specimen using electro magnetic FEM simulation results. Comparison of Johnson's theoretical normalized potential data with FEM simulation results was summarized as a function of normalized crack length in Figure 23. In the Figure 23, the blue line represents normalized potential results of Johnson's equation and the red dotted line is FEA simulation potential results, respectively. Comparing two results, Normalized FEA result is similar with theoretical value of Johnson Equation. Hence it can be concluded that DCPD method has a sufficient sensitivity for the application on real experiment.

\subsection{Potential Distribution (PD) analysis on axial crack}

Based on FEA sensitivity analysis, FEA simulation on real axial crack experiment geometry was performed. Figures 24 (a) and (b) show FE two-fold symmetry meshing model of SG tube and potential distribution contours without cracked specimen. As it is shown in Figure 24 (a), a constant current of 5 A was impressed through current leads having line-contacts with SG tube. To detect an axial crack evolution, the direct current was applied at the loading points so that the current flows along the circumference. Five sets of probe wires were attached with $2 \mathrm{~mm}$ spacing across the rectangular opening area, as shown in Figure 24 (a). Through potential distribution analysis on SG tube using FEM, initial DCPD potential drop result at each DCPD probe position can be forecasted before crack generation. Potential difference at each DCPD probe in SG tube specimen with no crack generation is predicted to be about $18 \mathrm{uV}$. For analyzing the potential drop of SG tube specimen as length and depth of crack increase, FEA simulation was performed for cracked tube with increasing crack depth gradually. Figures 25 (a) and (b) shows schematic of crack shape and FEM meshing model with crack that has a fixed a/c ratio of 0.1 , respectively. In Figure 25 (b), a distance between DCPD probes is set at 1mm. DCPD analysis of measured potential differences at each probe position as crack length at fixed aspect ratio increases gradually. The potential difference results at each point were summarized in graphic form in Figure 26. As shown Figure 26, as crack reach the DCPD probe location, DCPD signal is predicted to rise from $18 \mathrm{uV}$ slightly. As crack depth reach at $1 \mathrm{~mm}$, DCPD signal raises about 3 times the initial DCPD value. This FEA simulation results provide important data to establish repeatability of SG tube intergranular cracking specimen manufacturing, by comparison with measurement data obtained through experiments.

\subsection{Comparative study of DCPD method}

In this study, DCPD simulation using FEA was performed for improving the reliability of DCPD method in monitoring depth and length of crack. By analyzing change of potential drop data of DCPD FEA simulation on SG tube specimen with crack or not, DCPD method with array probes were expected to prove improvement of crack shape monitoring using direct current potential drop method. In this chapter, through the comparison with actuality experiment DCPD data, this FEA study results are basic reference data to verify measurements for production of cracked SG tube specimen, as demonstrated in the following reaction.

In order to assure that the probe arrangement provides DCPD signal in proportion to the crack depth, a penny-shape notch was produced on the tube by a diamond saw cut, DCPD signal at each probe set was measured as shown in Figure 27. For the range of experiment, there appeared to have a good correlation between the local crack depth and DCPD. When DCPD technique was applied to the $1 \mathrm{~mm}$ long axial intergranular crack, the measured signal was too small to recognize the crack formation. The non-detection of crack by DCPD was attributed to shallow crack depth as predicted by FEA stress analysis. When DCPD was applied to the second crack with $17.65 \mathrm{~mm}$ length, a systematic distribution of DCPD signal was observed. The results of DCPD and crack depth of $17.65 \mathrm{~mm}$ OD axial cracked specimen were summarized in Figure 28. Measured DCPD was normalized by the lowest value of each case and results are compared with those from the machined defect. As shown in Figure 7.29, consistent responses in DCPD signal were obtained by using the array probes.

Figure 7.30 shows comparative analysis result of DCPD signal of real experiment and predicted DCPD data using FEA of $25.4 \mathrm{~mm}$ ID axial crack. The numbers on this Figure represent locations measured DCPD signal. In Figure 7.30, blue rectangular point denotes FEA simulation results at each crack depth, and red diamond point denotes DCPD measured signal. At same crack depth, two data had a consistent difference of about $8 \mathrm{uV}$. But as a crack depth is deeper, measured DCPD signal was increased higher with similar ratio. From this result, it is confirmed that the application of DCPD in adequate.

Figure 7.31 shows result of DCPD signal of a real experiment of OD circumferential crack as a function of 
experimental time. As shown in Figure 7.31, DCPD data had a tendency to increase slowly after about 75 hours. In case that a crack was not generated in SG tube, DCPD data has about $25 \mathrm{uV}$. DCPD data was increased by value of $58 \mathrm{uV}$ after crack depth of $0.88 \mathrm{~mm}$ was produced finally. As a result, potential drop was increased more than about 2 times as the crack of final length was produced. Also, for the range of experiment, there appeared to have a good correlation between the measured DCPD data and predicted DCPD simulation data. The result on correlation was summarized in Figure 7.32. A difference of two data for final crack depth was about $13 \mathrm{uV}$, and this result was a slightly greater than difference of initial potential data, but general increasing characteristics of potential drop were very similar for both cases.

\section{CONCLUSIONS}

In order to produce a library of Laboratory-Degraded SG Tubes (LDT) with intergranular cracks, a radial dent loading method has been developed as a new method for generating ID and OD axial crack. By three-dimensional finite element analysis and experimental demonstration, it is confirmed that the radial dent loading can lead to long and shallow axial cracks that are more typical of actual degraded tubes in SG's.

However it was difficult to grow the axial crack into desired depths exceeding detection threshold of ECT by the method without allowing excessive plastic deformations. Therefore a two-step loading, the radial dent loading followed by an internal gas expansion loading, has been proposed as a versatile method for the control of crack aspect ratio and depth. From several experiments and finite element analysis, the direct tension loading method introduced to produce circumferential crack is verified to be a convenient and inexpensive loading method.

DCPD technique with array probes are demonstrated to be applicable and adequate for the new radial dent, direct tension, and internal expansion loading method for a two-step loading, for monitoring a crack with a significant depth. For confirmation and sensitivity evaluation of DCPD method, finite element analysis was performed for the electromagnetic problem which provided very useful insights into the method.

\section{ACKNOWLEDGMENTS}

This work has been supported by the Korean Nuclear R\&D Program organized by Korea Institute of Science and Technology Evaluation and Planning (KISTEP) in support of Korean Ministry of Science and Technology (MOST).

\section{REFERENCES}

[1] R.G. Ballinger and I.S. Hwang, "Characterization of Microstructure and IGSCC of Alloy 600 Steam Generator Tubing”, EPRI TR-101983 (1993)

[2] D. R. Diercks, et al., Steam Generator Tube Integrity Program, Annual Report, October 1996-September 1997, NUREG/CR-6511, Vol. 4, ANL-98/15, U.S. Nuclear Regulatory Commission, Washington, DC (March 1999).

[3] I.S. Hwang and I.G. Park, Control of alkaline stress corrosion cracking in pressurized water reactor steam generator tubing, Corrosion, Vol. 55, No. 6 (1999) pp. 616-625

[4] M.P. Landow and C.W. Marschall, Experience in Using Direct Current Electric Potential to Monitor Crack Growth in Ductile Metals, Elastic-Plastic Fracture Test Methods: The User's Experience (Second Volume), ASTM STP 1114, J.A. Joyce, American Society for Testing and Materials (1991) pp. 163-177

[5] "Standard test method for J-integral characterization of fracture toughness, ASTM E 1737-96", Annual book of ASTM standards, Vol. 03.01.

[6] I.S. Hwang, S.U. Kwon, S.G. Lee and J. H. Kim, An Intraspecimen Method for the Statistical Characterization of Stress Corrosion Crack Initiation Behavior, Corrosion 57(2001), pp.787-793.

[7] I.S. Hwang, Embitterment Mechanisms of nickel-base Alloys in Water, MIT Ph. D. Thesis (1987)

[8] ASTM Standards E8, ASTM (1996) 
Table 1. Chemical analysis on Alloy 600 tube [\% unit]

\begin{tabular}{|c|c|c|c|c|c|c|c|c|c|c|c|c|c|}
\hline$t$ & 긱 & 14 & 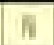 & 0 & 7 & 3 & 8 & 4 & 1 & $\bar{y}$ & $a$ & $\mathrm{Fi}$ & 8 \\
\hline 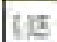 & 118 & $0 \mathrm{~d}$ & Bat & 159 & 108 & 000 & war & Q1: & $0 y$ & uns & 0,00 & va & $0 \mathrm{OCH}$ \\
\hline
\end{tabular}

Table 2. Mechanical and metallurgical test results of this SG tube [\% unit]

\begin{tabular}{|c|c|c|c|c|c|c|c|}
\hline & Treabiat & & & \multicolumn{3}{|c|}{ Motifyesingt } & \\
\hline $\tan [\mathrm{C}]$ & A.9 T.SIR. & IS.S.R. & $E[F]$ & crie & malives & inderes 15 & carrais \\
\hline 20 & 22,5 & $\Delta .5$ & $A$ & 4050 & $\begin{array}{l}17 . N-00 \\
8 \times-0\end{array}$ & 6 & $n$ \\
\hline
\end{tabular}

Table 3. Modified Huey test result for as-received and sensitized Alloy 600 tube

\begin{tabular}{|c|c|c|c|c|c|c|}
\hline 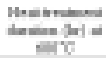 & -4 & u & $w$ & at & $=$ & $\pi$ \\
\hline Maje in: & 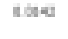 & tanei & tonos & 6.0431 & ànetil & Iebive: \\
\hline
\end{tabular}

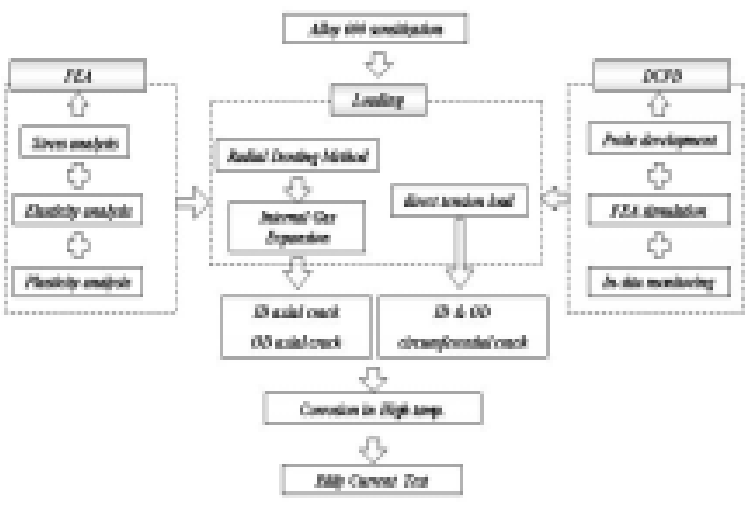

Fig. 1 The schematic of goals and approach of this thesis

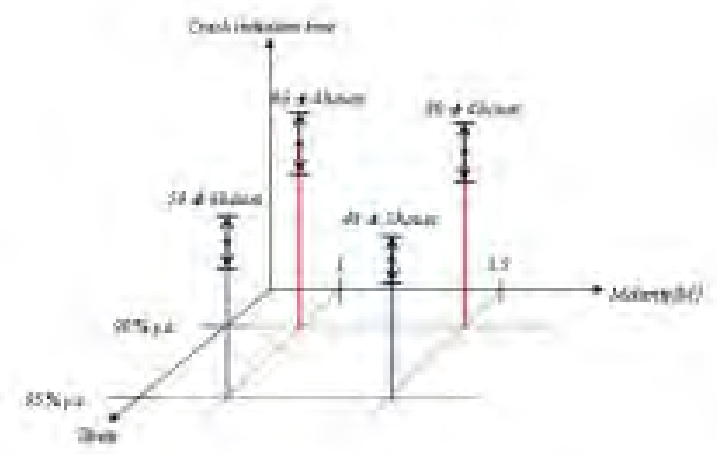

Fig. 2 Result of crack initiation time as a function of Na-tetrathionate concentrations and loads

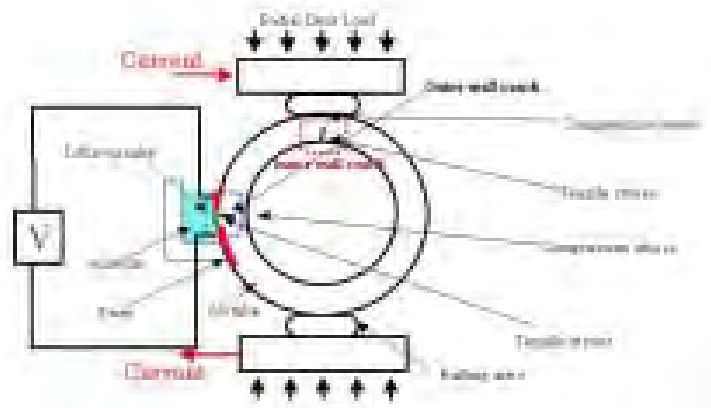

(a) The axial cracking at outer surface

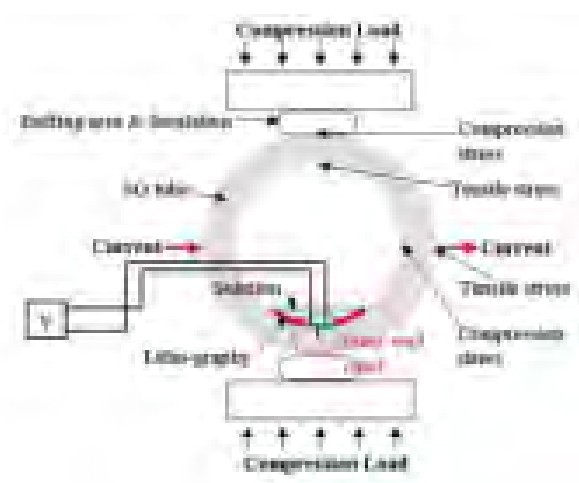

(b) The cracking at inner wall surface

Fig. 3 Schematic of the radial denting method applied for the axial cracking at either outer or inner surface

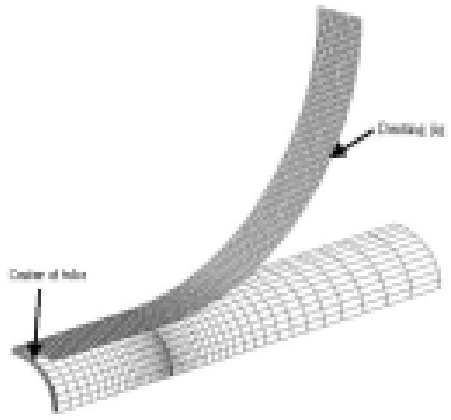

Fig. 4 Finite Element Mesh structure used in finite element analysis of dent loading

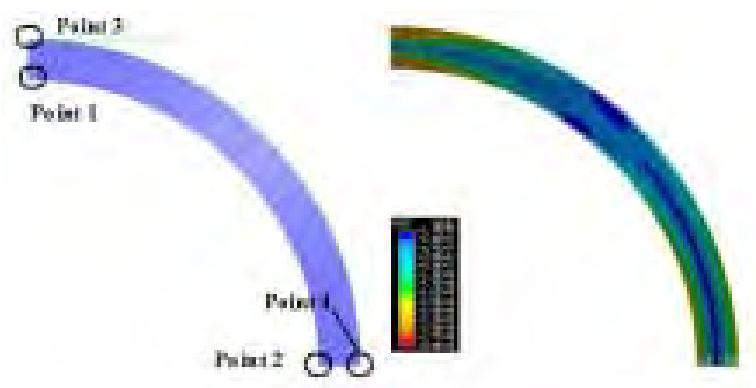

(a) Meshing for cross section (b) Stress distribution in cross-section

Fig. 5 Stress distribution in the tube cross section of a dent loaded tubes 


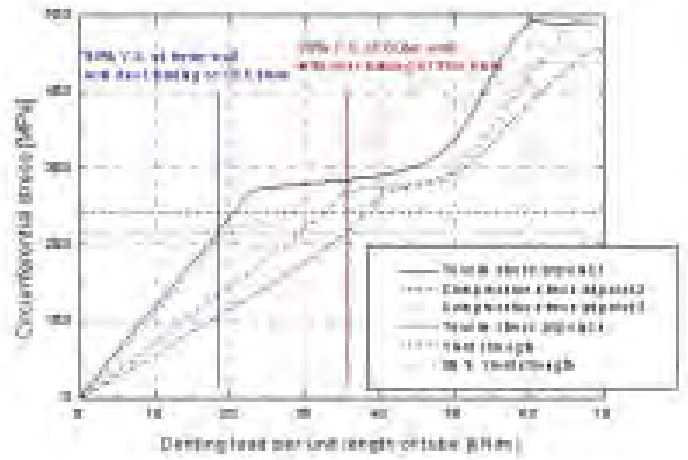

Fig. 6 Circumferential stress distribution at each position as a function of denting load per unit axial length (location of each Point is defined in Figure 5

(a))

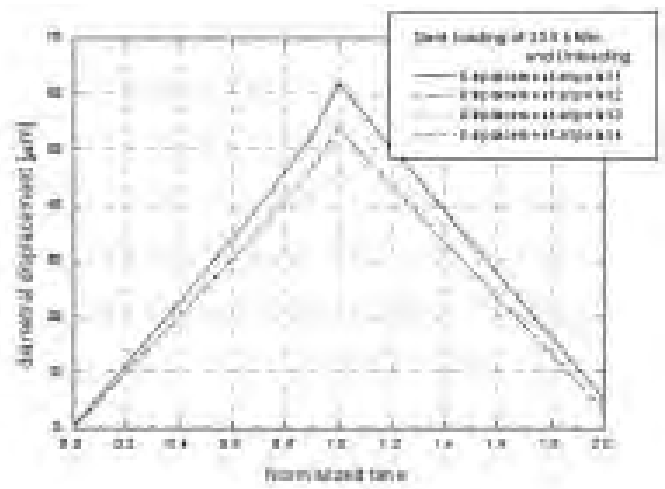

Fig. 7 Diametric displacements corresponding to initial position with loading to $35.6 \mathrm{kN} / \mathrm{m}$ followed by unloading (location of each Point is defined in Figure 5 (a))

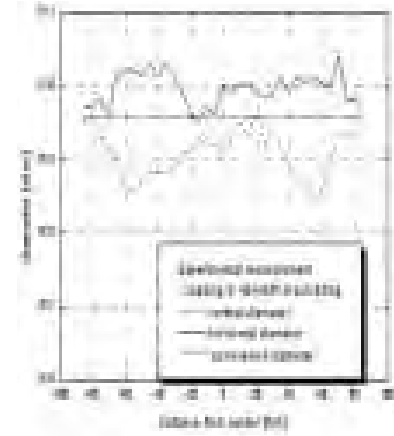

(a)

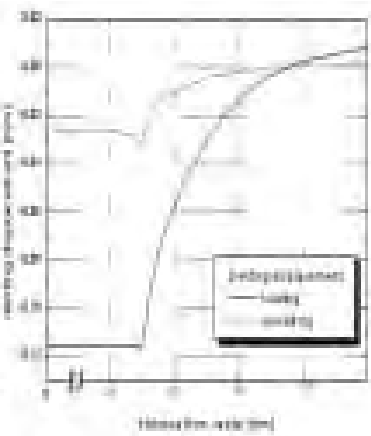

(b)
Fig. 8 Vertical diameter changes measured (a) and predicted by three-dimensional FEA (b) after a radial dent loading to $40.0 \mathrm{kN} / \mathrm{m}$ followed by unloading

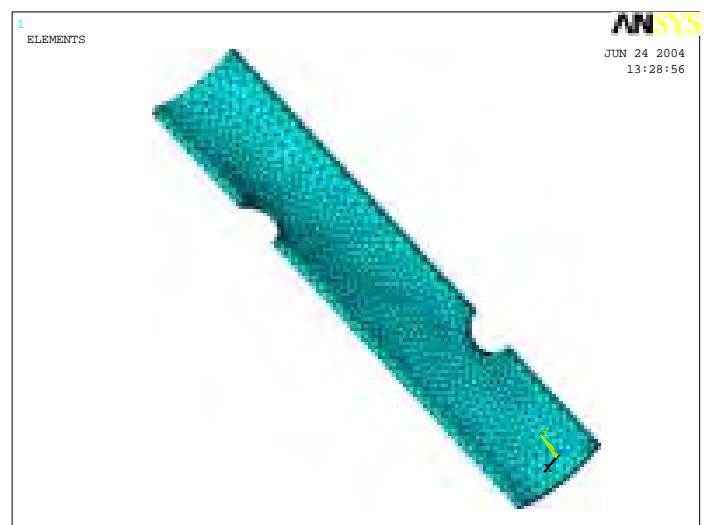

Fig. 9 Finite Element Mesh structures employed for the tube taking into account a four-fold symmetry
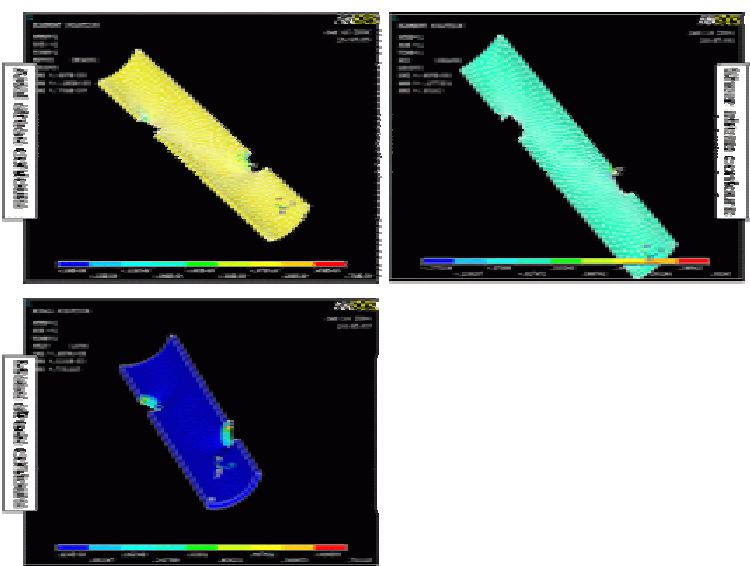

Fig. 10 Predicted shear stress, Von Mises stress and axial stress distribution contours under direct tensile loading

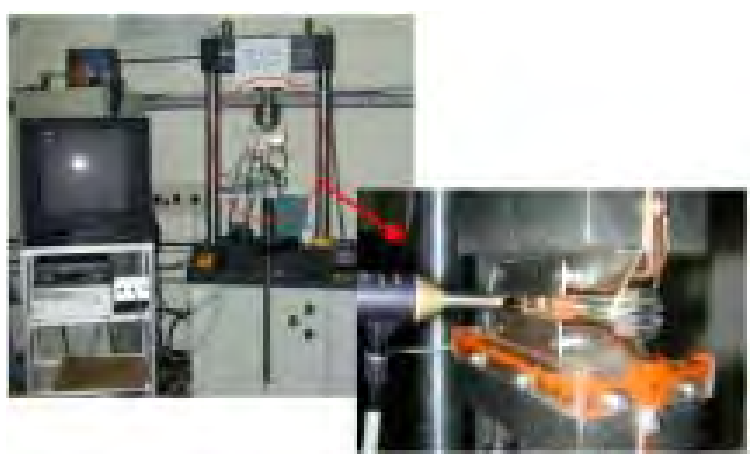

Fig. 11 Dent loading test apparatus with DCPD and observation microscope. 


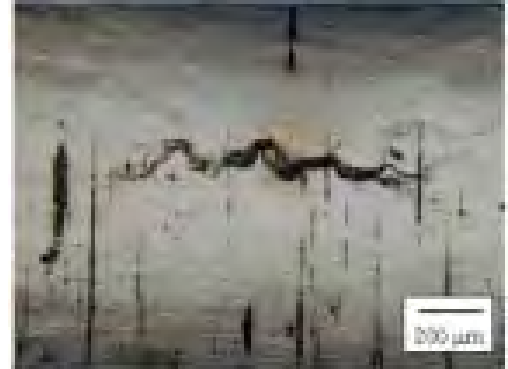

(a) Surface axial crack produced at the first experiment

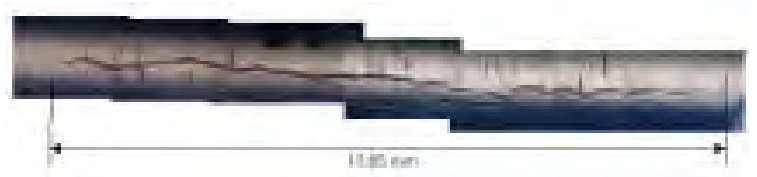

(b) Surface axial crack produced in the second experiment

Fig.12 Surface axial crack produced on the tube outer surface by the radial dent loading

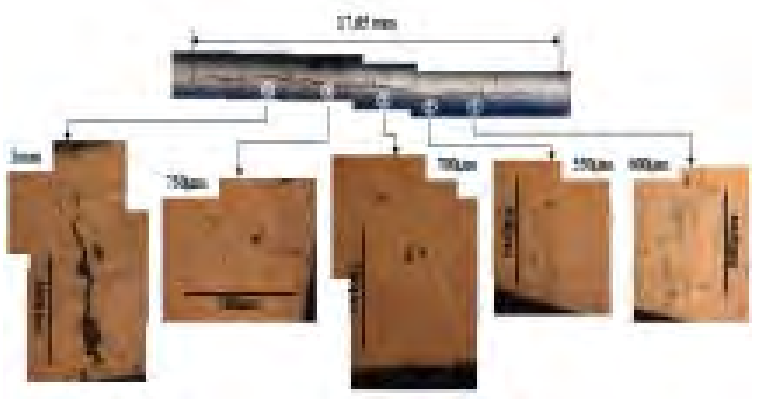

Fig. 13 Destructive examination of $17.65 \mathrm{~mm}-\mathrm{OD}$ long and shallow crack and sectioned area for confirming the crack depth, (Numbers represent locations of DCPD probe)

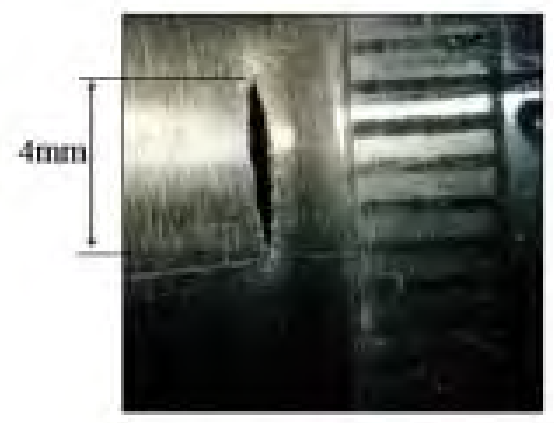

Fig. 14 Results of OD circumferential crack generation by the direct tensile loading

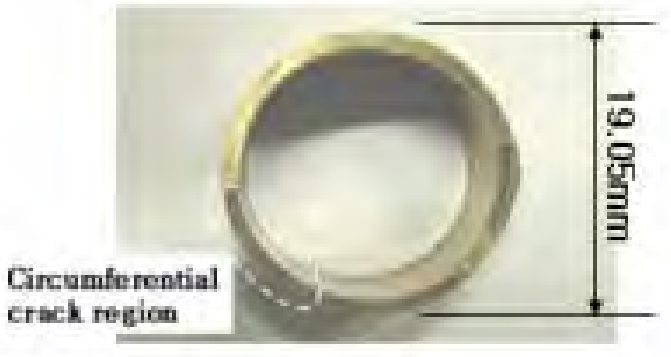

(a) Sectioned area of cracked tube for SEM observation

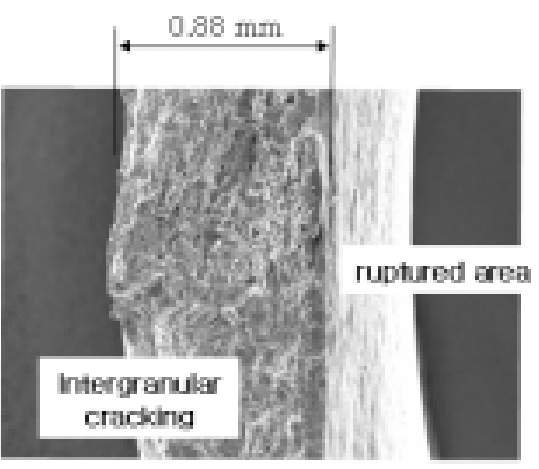

(b) SEM micrograph of whole section of tube wall Fig. 15 Scanning electron microscope (SEM) observation on fracture surface of circumferential crack after rupture

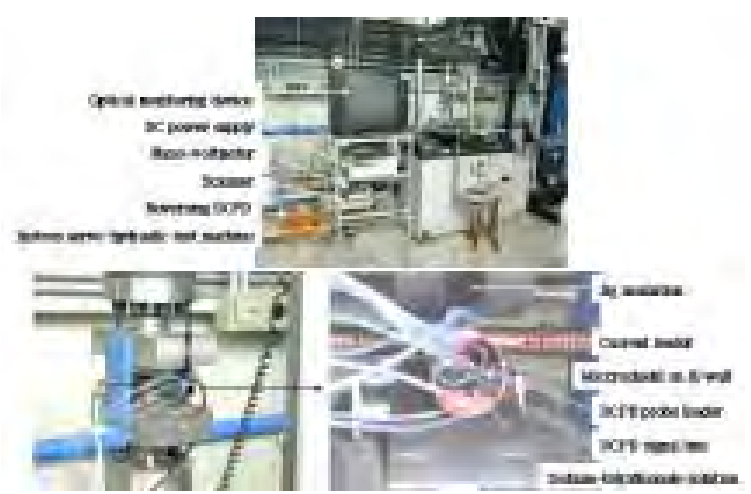

Fig. 16 Overview of apparatus for ID axial generation (Applying Direct Current Potential Drop method)

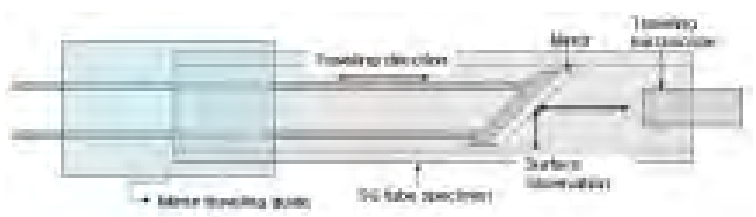

Fig. 17 Schematic of traveling microscope technique to confirm initiation condition of crack, as in-situ monitoring method for inner wall crack generation 


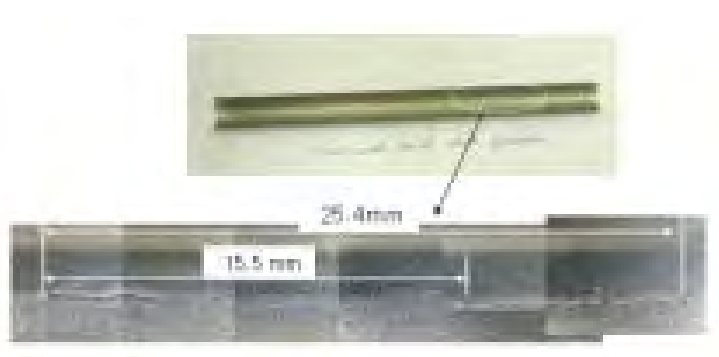

Fig. 18 Result of OD axial crack generation by the radial dent loading (ID cracked tube was cut in half)

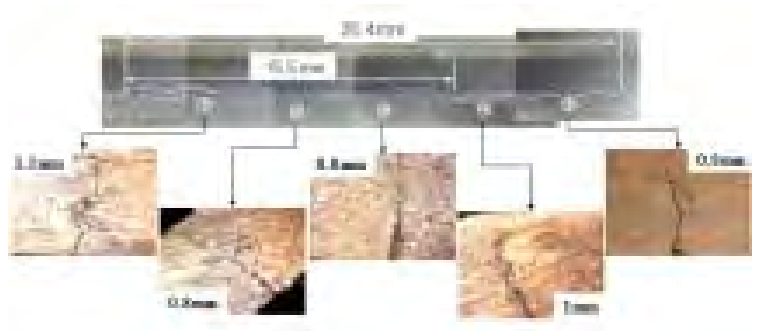

Fig. 19 Destructive examination of $25.4 \mathrm{~mm}$-ID long and shallow crack and Sectioned area for confirming the crack depth, (Numbers represent locations of DCPD probe)

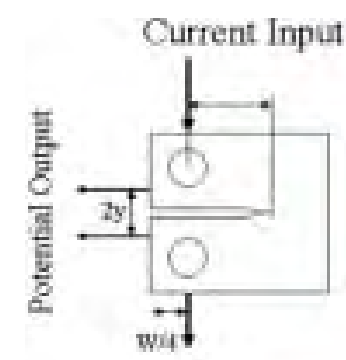

(a)

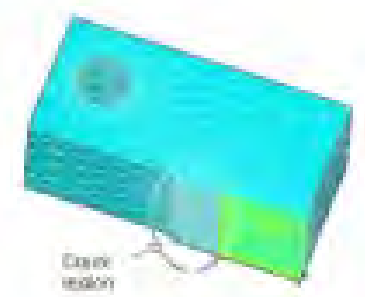

(b)
Fig. 20 Schematic of DCPD FEA simulation model and FEM meshing model

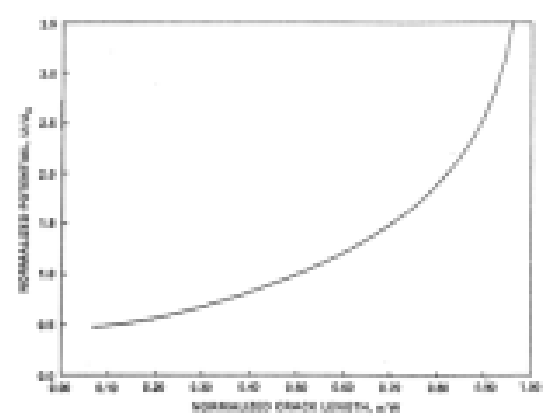

Fig. 21 Johnson's theoretical normalized potential data as a function of normalized crack length showed in graphic form

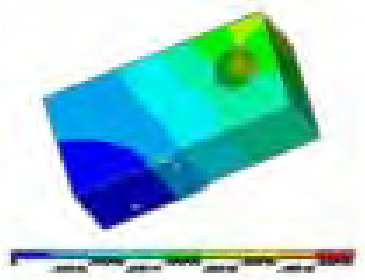

(a)

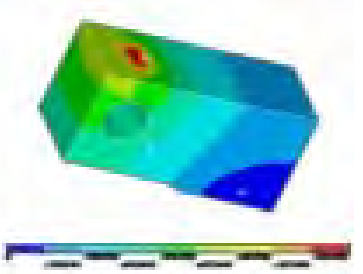

(b)
Fig. 22 Potential contours of CT specimen using electro magnetic FEM simulation results

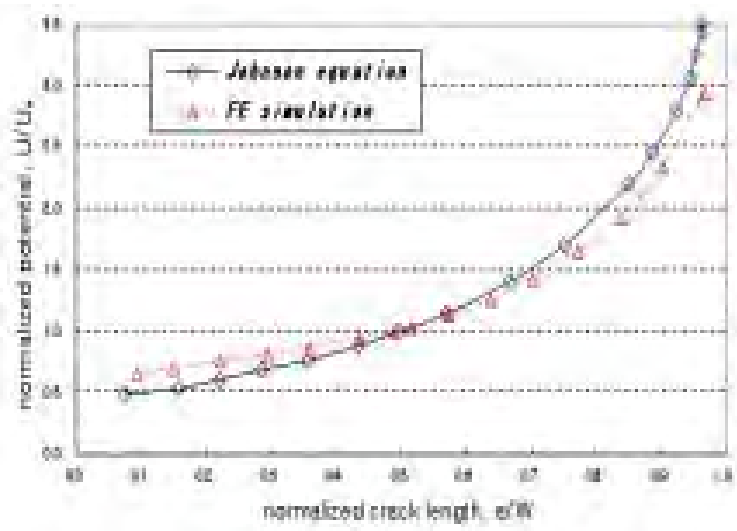

Fig. 23 Comparison result of Johnson's theoretical normalized potential data with FEM simulation results as a function of normalized crack length

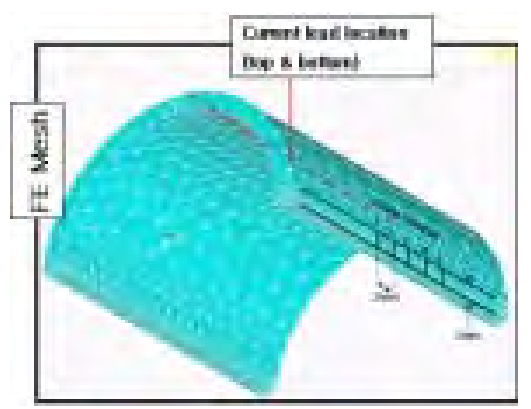

(a) FE $1 / 2$ meshing model for analysis DCPD simulation of axial crack generation

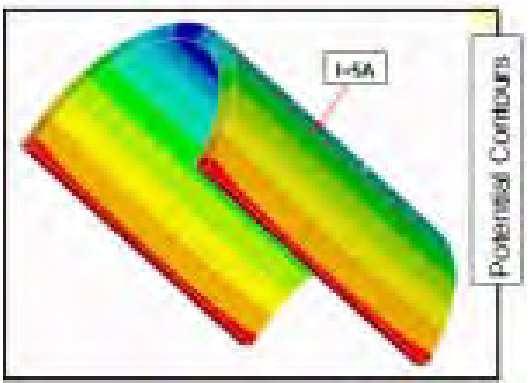

(b) Predicted potential contours of SG tube specimen without crack

Fig. 24 Two-fold symmetry FEA meshing model and predicted potential contours of Alloy 600 tube specimen without crack 


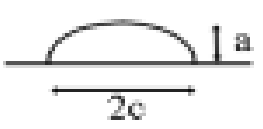

Fboed value $: a / c=0.1$

(a) Schematic of OD axial crack shape

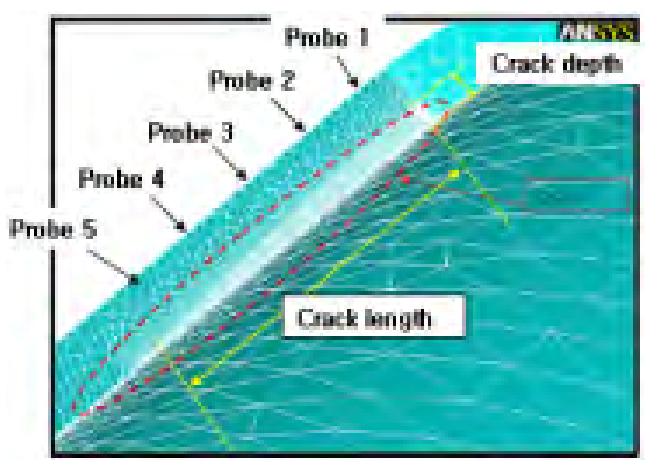

(b) FEM meshing model with crack that has 0.1 fixed a over c ratio

Fig. 25 Schematic of crack shape and FEM meshing model with crack a/c ratio of 0.1

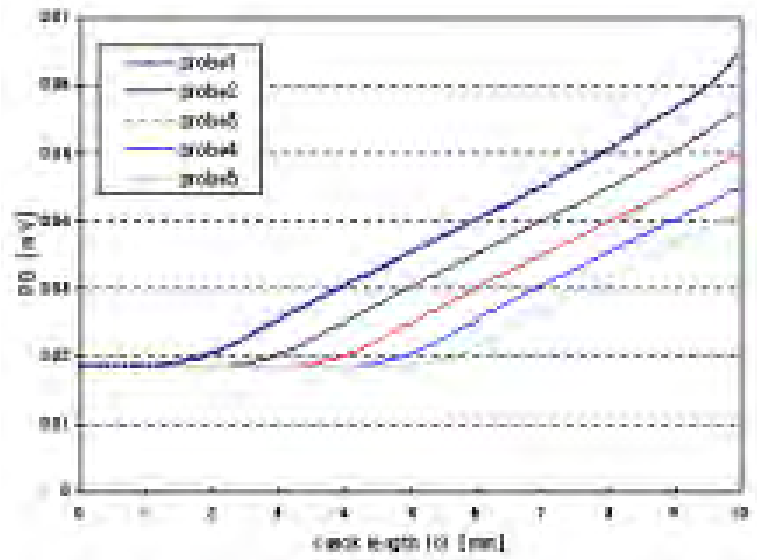

Fig. 26 Predicted DCPD increase as results of OD axial crack at each DCPD probe position as a function of crack length growth

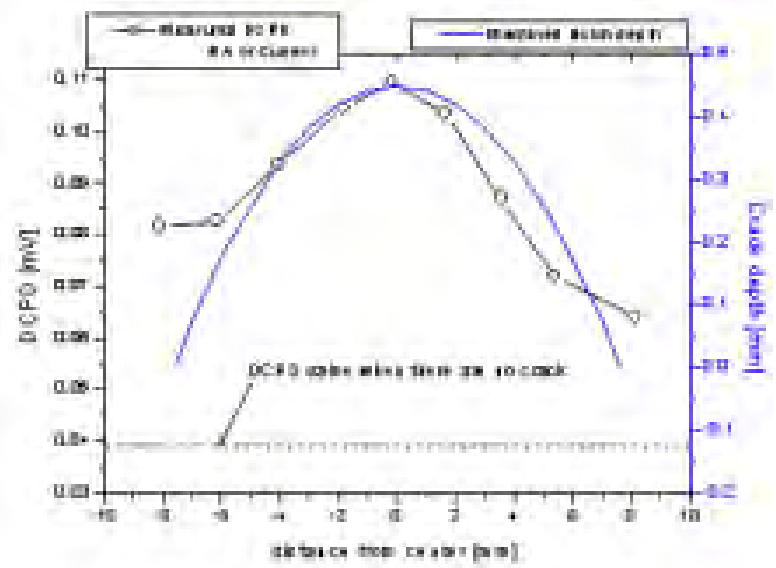

Fig. 27 DCPD measurements from the probe arrangement were compared with the actual crack depth of a penny-shape machine notch produced by diamond saw-cut.

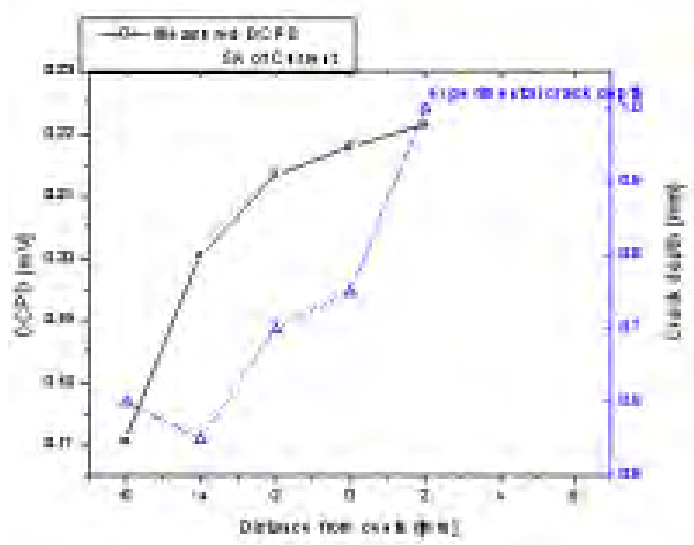

Fig. 28 DCPD signal in proportion to the crack depth for the $17.65 \mathrm{~mm}$ long intergranular OD axial crack

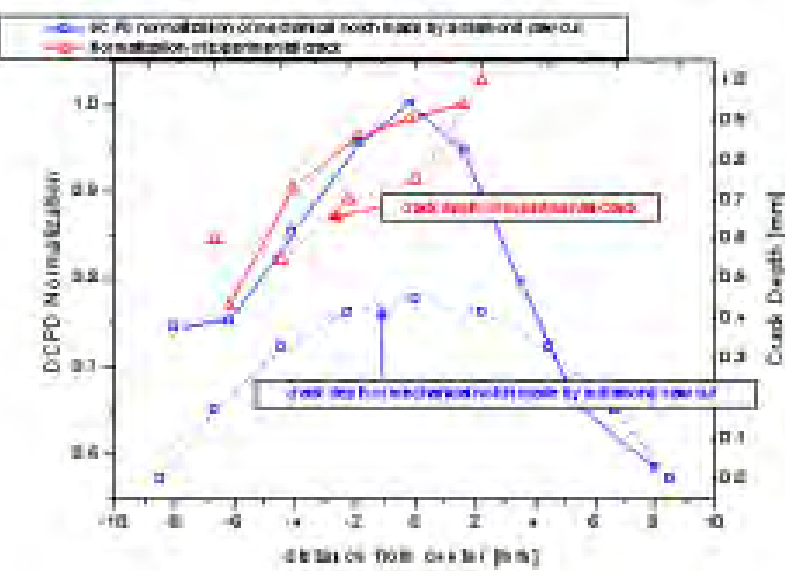

Fig. 29 Normalized DCPD signals and flaw depth for a mechanical notch and for the $17.65 \mathrm{~mm}$ long intergranular crack as a function of axial distance from the specimen center. 


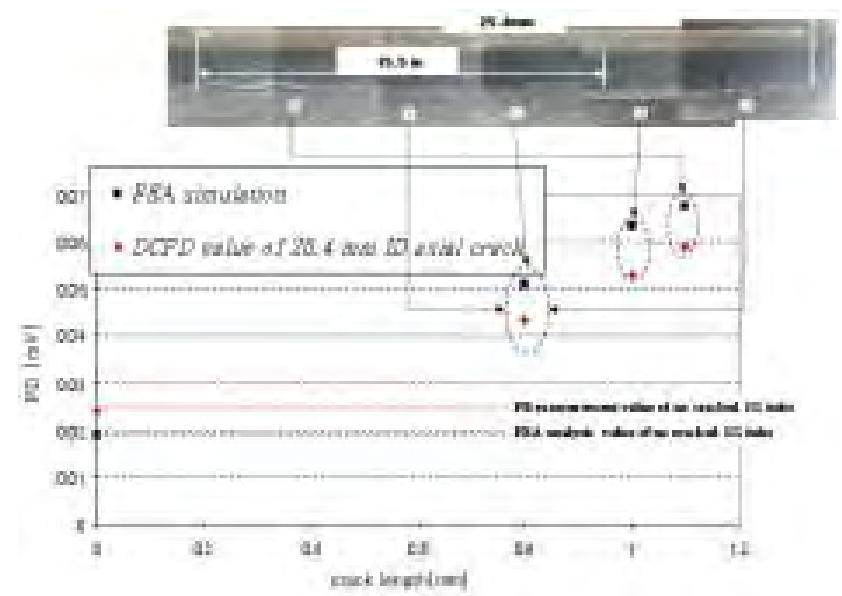

Fig. 30 Comparison of measured DCPD signal and predicted DCPD data using FEA of $25.4 \mathrm{~mm}$ ID axial crack

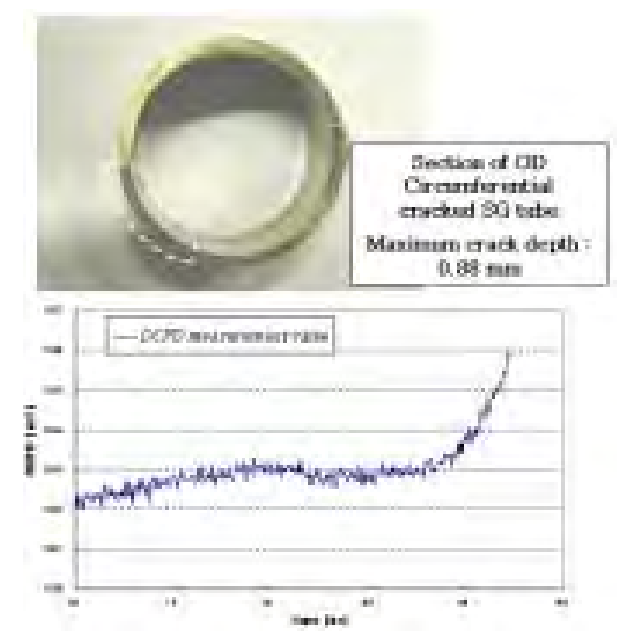

Fig. 31 Result of DCPD signal of real experiment for OD circumferential crack as a function of time

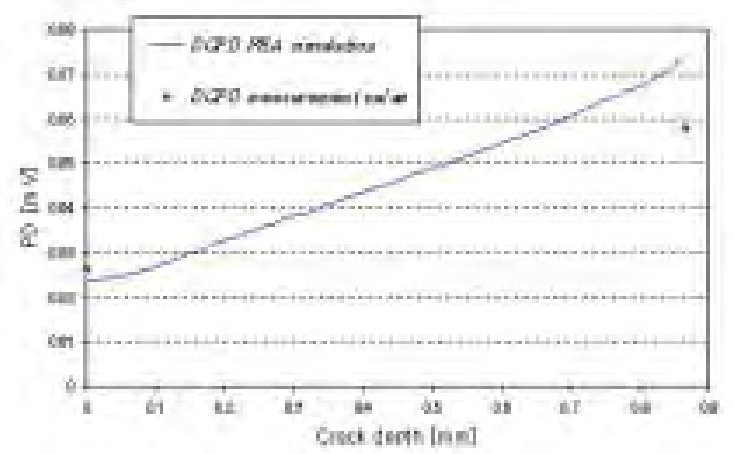

Fig. 32 Result of correlation analysis between the measured DCPD data and predicted DCPD simulation data for an OD circumferential crack 